\title{
A RECONSTRUÇÃO DA UTOPIA: A QUEM COMPETE ESSA TAREFA?
}

\author{
FRANCISCA VIRGIINIA SOARES 1
}

SOARES, Francisca V. A reconstrução da utopia: a quem compete essa tarefa? Semina: Ci. Sociais/Humanas, Londrina, v. 17, n. 3, p. 260-265, set. 1996.

RESUMO: Este artigo é uma reflexão sobre o modernismo e a globalização e suas conseqüências na sociedade. Sua idéia principal é se apoiar no fato de que a cultura pode ser utilizada para revisar estes problemas na construção da nova utopia.

PALAVRAS-CHAVE: Modernidade, Pós-Modernidade, Globalização, Ideologia, Utopia, Cultura, Subjetividade Capitalismo, Socialismo, Liberalismo, Esquerda, etc.

\section{INTRODUÇÃO}

Karl Marx escreveu, em 1848, em seu clássico O Manifesto Comunista, que um espectro ronda a Europa, é o espectro do comunismo. Quase 150 anos depois, pode-se afirmar que esse espectro sucumbiu, pelo menos, o espectro do comunismo real, ortodoxo, stalinista e unitário. A contemporaneidade contempla um outro tipo de espectro que ronda não só a Europa, mas toda a humanidade: a (pós) modernidade e a globalização. Conceitos estes que diversos autores discutem sem, no entanto, defini-los textualmente.

O que nos parece exequível é que, pensar tais questões tornou-se um desafio intelectual às várias áreas das ciências sociais. Neste sentido, devemos aproveitar a discussão e a provocação neo-liberal de que a história e o marxismo estão mortos e enterrados para refletir esta difícil e complexa problemática.

Este ensaio tem como pressuposto básico a idéia de que a cultura é um veio imprescindível para se analisar este tema contraditório e inesgotável que é a (pós) modernidade e suas conseqüências. Uma dessas conseqüências amplamente difundidas, principalmente, pela mídia, refere-se ao fim das ideologias, da história e da própria utopia. Se tal afirmação é correta, é possível resgatá-las? E se se for possível, de que modo fazê-lo?

\section{A CULTURA NÃO É UM VALOR UNIVERSAL: É UM MODO DE PRODUZIR SOCIABILIDADES A PARTIR DA DIFERENÇA}

Não nos referimos aqui, "(...) às mais de quatrocentas definições que o conceito de cultura experimentou em vários momentos da história da antropologia (...) que em todos eles a cultura sempre foi estudada como dominação explícita da natureza, como algo que estaria próximo de um operador de domesticação de forças incontidas. Essas definições, porém, acabaram (...) transformando-se em modelos ideológicos (...)". (CARVALHO, 1994:110). E que, não raro, nos remete a pensála como sendo um valor universal, se formos considerar o paradigma da globalização.

Referimo-nos, todavia, à visão instrumental de cultural, mais precisamente, como organizar uma cultura que possibilite "construir um mecanismo para selecionar e desenvolver as capacidades individuais da massa popular, que hoje são sacrificadas e definham em erros e tentativas sem perspectivas". (GRAMSCI, 1986:126).

Isto posto, perguntaríamos: quem, do ponto de vista, prático ou da inserção social, estaria habilitado para tal tarefa? E essa questão nos remete, antes de tudo, a refletir sobre a modernidade/globalização e dentro desse binômio, refletir também e principalmente, na subjetividade dos diversos sujeitos envolvidos no processo de mudanças. Estas que, devem ser também mudanças estruturais em termos culturais e sociais, condições essenciais para vislumbrar uma nova utopia que nos tire do imobilismo e do pessimismo que, ao que tudo indica, mergulhamos. Em outras palavras, é o que Maria de Lourdes Manzini-Covre definiu como revolução cultural de valores ou o emergir de sujeitos novos. (COVRE, 1994:). Ou, como bem lembrou Félix Guatarri, "em nome do primado das infra-estruturas, das estruturas ou dos sistemas, a subjetividade não está bem cotada, e aqueles que dela se ocupam na prática ou na teoria em geral, só a abordam usando luvas, tomando infinitas precauções, cuidando para nunca afastá-las demais dos paradigmas pseudo-científicos tomados de empréstimo, de preferência, às ciências

\footnotetext{
1 - Professora Titular de Sociologia das Faculdades Integradas Cândido Mendes - Rio de Janeiro.

Aluna do Programa de Pós-Graduação - Doutorado em Ciências Sociais na Pontifícia Universidade Católica - PUC/SP.
} 
duras (...)". (GUATARRI, 1993:18).

Muitos autores, com seus diferentes paradigmas, são chamados para essa reflexão, como Anthony Giddens, Marshal Berman, Jean-François Lyotard, Jurgen Habermas, Nestor Garcia Canclini, José Machado Paes, Maria de Lourdes M. Covre, Walter Benjamin, Francisco de Oliveira e tantos outros. Todos por sua vez, tendo como fornecedores de suas idéias, Platão, Rousseau, Goethe, Hegel, Karl Marx, Nietzsche, Max Weber, etc. Estes que foram humanistas que se debruçaram sobre temas que também desafiaram intelectualmente (e materialmente) a modernidade de suas respectivas épocas.

Não contemplaremos, no entanto, todos esses autores em nossa abordagem, tendo em vista a abrangência do assunto. Contudo, procuraremos citar um e outro quando for conveniente, com destaque para alguns que, de um modo mais direto, têm mais a dizer sobre o tema cultura. Desse modo, acreditamos que pensar sob a ótica do relativismo é, em nossa visão, fundamental, posto que devemos procurar neste fim de milênio, alternativas que possibilitem elaborar modelos que propiciem a construção de um "humanismo de novas roupagens, superador das certezas cristãs, que apostavam na unidade do gênero humano (...)". (CARVALHO, op cit).

Temos convicções de que é possível acenar para essa utopia. Daí nossa crença, de que refletir a partir da compreensão dos significados do conceito de cultura, parece ser um dos caminhos. Tendo em vista que "não há, nem pode haver, uma civilização mundial no sentido absoluto que comumente se atribui a esse tempo, porque a civilização implica a coexistência de culturas que apresentam entre si o máximo de diversidade e consiste nessa coexistência". (STRAUSS, 1973:417). Essas observações de Lévi-Strauss são bastante pertinentes e atuais, posto que nos chamam a atenção ao fato de que "(...) não é de se espantar que as ciências humanas e as ciências sociais tenham se condenado por si mesmas a deixar escapar as dimensões intrinsecamente evolutivas, criativas e autoposicionantes dos processos de subjetivação. (...). Parece urgente desfazer-se de todas as referências e metáforas científicas para forjar novos paradigmas que serão, de preferência, de inspiração ético-estéticas". (GUATARRI, op cit).

Temos claro que essa coerência e sentido devem ser entendidos não como unificação, visão etnocêntrica, linear, mas como forma de pertencimento social ou qualidades que devem sustentar determinadas formações sociais ou grupos, a partir de sua produção cultural. Na verdade, essa coerência nos remete à compreensão e decifração dos símbolos, dos códigos, dos mitos e signos que permeiam o imaginário social. O estruturalismo de Lévi-Strauss é, nesse sentido, fundamental para nos explicar que o conjunto desses elementos corresponde à estrutura simbólica que corresponderia ao inconsciente. Ou seja, cada uma dessas estruturas simbólicas têm suas características próprias e seus códigos específicos. (LÉPINE, 1974).

\section{GLOBALIZAÇÃO E (PÓS) MODERNIDADE: MONOLITOS FECHADOS E EXCLUDENTES}

No que diz respeito aos termos modernidade, pósmodernidade e globalização, os mesmos parecem exercerem um certo fascínio e encanto sobre os indivíduos. A nosso ver, isso ocorre por não terem definições claras, na maioria das vezes "(...) ou (são vistos) com um entusiasmo cego e acrítico ou (são) condenado(s) segundo uma atitude de distanciamento e indiferença, (...) (são) sempre concebidos como um monolito fechado (...)". (BERMAN, 1986:24).

Pensando nesta perspectiva de Berman, tais conceitos parecem igualar-se ao vazio, à repetição, à mediocridade, posto que há uma fragmentação e uma insuficiência para inovar ou criar nos mais diferentes campos do conhecimento. Dito de outra forma ou citando mais uma vez Berman, há uma ausência daquilo que ele chamou de "experiência vital". E ao invés de celebrar a (pós) modernidade e a globalização, devíamos sim, questionar as conseqüências advindas das mesmas.

Em termos políticos, uma das conseqüências mais visíveis é uma certa desmobilização, principalmente em relação aos partidos políticos de esquerda. Estes que historicamente sempre representaram uma alternativa às intransigências liberais, não conseguem elaborar uma nova agenda que responda aos principais temas e debates da atualidade, como por exemplo, a globalização. A crítica que se deve fazer, é que a esquerda corre o risco de perder sua identidade própria, perder suas raízes e, portanto, seu rumo, uma vez que está se distanciando dos movimentos sociais, espaço onde, efetivamente, deve se dar a sua prática. Ressaltamos que nos referimos à esquerda brasileira e particularmente, à crise que presenciamos em seu bojo. Ela que parece estar ligada a duas derrotas importantes: a eleição presidencial e a reforma da ordem econômica.

Esgotaram-se as bandeiras de luta? Errado. Esgotaram-se, a nosso ver, a forma de fazer política, tendo a mesma se distanciado das bases populares e de suas mañifestações distanciado das bases populares e de suas manifestações culturais. Estará a esquerda se aproximando da direita, tendo em vista que sua agenda, não raro, confunde-se com aquela? Em suma, será que o discurso neo-liberal é o grande vencedor? Será que as ideologias estão mesmo mortas e enterradas? Terão elas se desmanchado no ar sombrio da (pós) modernidade? Como resgatá-las?

Na realidade, essas questões estão por toda parte, por todo o mundo, porque a globalização se encarregou de disseminar uma nova cultura: a cultura da despolitização, o que parece ser uma das marcas deste período que vivenciamos. Disto resultou que nos tornamos "sujeitos sujeitados", como frisou Manzini-Covre, onde nossas identidades culturais de cunho regional e local, nossas qualidades pessoais e espirituais, foram substituídas pela cultura do consumo.

Talvez, pudéssemos afirmar que o esvaziamento da subjetividade dos sujeitos, de suas consciências

Semina Ci. Sociais/Hum., v. 17, n. 3, p. 260-265 
de classe e de suas reais necessidades, em grande parte, tenha tido como causa um cenário, onde os "meios técnicos (...) mais sofisticados, como o satélite, o cabo, a utilização de outras freqüências, de um lado; e de outros aparelhos como o video-cassete, o computador (...) ou as filmadoras portáteis estariam levando a transformações tanto no âmbio da produção, quanto no dos usos da cultura industrializada". (MIRA, 1994:135).

Esse cenário robótico, cibernético e racionalizado nos remete à visão weberiana de desencanto do mundo sobre a vida moderna. Como observou Berman ao mencioná-lo, "(...) não só a sociedade moderna é um cárcere, como as pessoas que aí vivem foram moldadas por suas barras; somos seres sem espírito, sem coração, sem identidade sexual ou podíamos dizer: sem ser". (BERMAN, op cit:27).

Anthony Giddens acende-nos várias luzes que nos fazem pensar que os acontecimentos acima seriam as próprias conseqüências do que muitos classificam como (pós) modernidade. De acordo com ele, "hoje no final do século $X X$, muita gente argumenta que estamos no limiar de uma nova era, à qual as ciências devem responder e que está nos levando para além da própria modernidade (...) uma (...) variedade de termos tem sido sugerido para esta transição (...) um novo tipo de sistema social (tal como 'sociedade de informação' ou 'sociedade de consumo'). Não basta meramente inventar novos termos, como pós-modernidade e o resto, mas olhar mais atentamente para a natureza da própria modernidade. (...). Em vez de estarmos entrando num período de pós-modernidade, estamos alcançando um período em que as conseqüências da modernidade estão se tornando mais radicalizadas e universalizadas do que antes". (GIDDENS, 1991:13).

Conseqüentemente, é este cenário que precisa ser pensado criticamente e, assim, buscar nele próprio sinais que nos aponte para um novo projeto de modernidade. Que seja centralizado nas forças populares para resgatar as questões sociais numa nova perspectiva. Isso implica em centralizar questões como: o que são políticas públicas e qual o significado de Estado ou do Estado do bem-estar? (OLIVEIRA, 1988 e 1993). Não estaria o Estado tal qual o conhecemos obsoleto, nesta era contemporânea? Daí as várias conseqüências advindas com sua superação?

Para refletirmos sobre estas e as demais questões que expomos, recorremos mais uma vez a Guatarri, o qual diz que "não podemos nos deixar guiar cegamente pelos tecnocratas dos aparelhos de Estado para controlar as evoluções e conjurar os riscos nesses domínios, rígidos no essencial pelos princípios da economia de lucro. (...). Jamais o trabalho humano ou o habitat voltarão a ser o que eram há poucas décadas, depois das revoluções informáticas, robóticas, depois do desenvolvimento do gênio genético e depois da mundialização do conjunto dos mercados". (GUATARRI, op cit:24).

Como exemplo do enunciado acima, podemos citar o Brasil, ele que "(...) vive uma guerra civil de baixa intensidade ( $\ldots)$, uma sociedade (...) com desagrega- ção, miserabilidade e deslocamentos populacionais, ou seja, todo um processo humano social de violência e de cotidianidade. (...). Um genocídio social, com descartabilidade e darwinismo. O quadro brasileiro é neodarwinista. É pior do que hobbesiano, é pior do que o do século XVIII. Nossa fome não tem uma sociedade agrária, portanto, não tem defesa". (OLIVEIRA, 1993:24).

Vemos então que, tentar compreender a pósmodernidade ou a globalização é descartar os reais problemas da modernidade, como os descritos acima. É desviar as discussões daquilo que Giddens assinalou, como sendo as conseqüências de um período histórico que já foi classificado de modernidade. É cair no vazio, posto que esses termos sugerem a excludência do sujeito, de sua subjetividade, ou seja, homens são participativos e fragmentados de si mesmos e dos outros.

Jean-François Lyotard advoga que o termo pósmoderno, enquanto condição da cultura nesta era, caracteriza-se exatamente pela incredulidade diante do discurso filosófico-metafísico, com suas pretensões atemporais e universalizantes. Apregoa ele que o cenário pós-moderno é essencialmente cibernéticoinformático-informacional, sendo que "nele, expandemse cada vez mais os estudos e as pesquisas sobre a linguagem, com o objetivo de conhecer a mecânica da sua produção e de estabelecer compatibilidades entre linguagem e máquina informática, (...) neste cenário predominam os esforços (científicos, tecnológicos e políticos) de informatizar a sociedade". (LYOTARD, 1994:Vii).

Esta perspectiva de Lyotard se detém no aspecto puramente informático e científico, visando avaliar as condições do saber produzido nas sociedades mais desenvolvidas. Sem, no entanto, nomear os conjuntos de processos sociais significativos, como o faz Giddens, ao refletir sobre os conceitos mencionados enquanto um projeto ligado aos aspectos dos recursos políticos, econômicos e sociais.

\section{CULTURAS POPULARES: AS "VERDADES" DOS CORPOS TOMBADOS}

Para contrapor a visão de Lyotard, onde a cultura é um fator, a nosso ver secundário, relembramos a preocupação de Gramsci quando da sua tentativa em entender a Itália de sua época. Ele lançou algumas interrogações que, mostrava a importância de se priorizar a produção da cultura popular ou operária, em face da hegemonia da cultura da elite. Então ele dizia: "como vou compreender a Itália? Como é que se pode criar uma cultura operária hegemônica em um país que é católico e que tem 60 dialetos? Como se dá esse processo? Você pode subsumir tudo numa unidade nacional? O caminho para a hegemonia, é resgatar essas identidades regionais num novo projeto nacional".

Estas questões são pertinentes também para a reflexão a que nos aventuramos, pois possibilita o deslocamento para o enfoque da heterogeneidade cultural. Frisamos mais uma vez, caminho imprescindível para a construção de uma sociedade mais ética, como novos 
valores e a reafirmação daqueles que até agora contribuíram para a compreensão da realidade social. É neste sentido que Gramsci, Walter Benjamin e tantos outros críticos nos fornecem as ferramentas necessárias para resgatar as identidades que foram moldadas pela cultura midiática, numa perspectiva global. Ambos os autores nos desperam para a cultura submersa nos meandros marginalizados, onde "os despojos são carregados no cortejo (...). Esses despojos são o que chamamos bens culturais (...). Nunca houve um momento da cultura, que não fosse também um momento da barbárie (...)". (BENJAMIN, 1985:225).

Não é possível reproduzir Benjamin e Gramsci na íntegra. Pode-se, contudo, utilizar suas teorias para mostrar o massacre a que foi submetida a cultura das minorias. Como no caso dos índios, dos negros, das religiões que não fossem o catolicismo, das crianças de ruas, das mulheres, dos judeus. Enfim, além desses, tantos outros gurpos minoritários tiveram ou têm massacrados os seus valores e bens culturais ao nível de "mercadorias". Podemos ilustrar a intolerância por parte da sociedade aos grupos funk quanto à sua música, modo de vestir, dançar, falar, etc. Estes que, incorporaram, principalmente, jovens das camadas pobres, existem enquanto atividade de lazer, forma de manifestação cultural e o que é mais importante: é um modo desses indivíduos se sentirem integrados a um grupo social. No entanto, por não terem sido (ainda) incorporados pela mídia, o funké visto como "grupos que provocam a violência".

Em suma, é essa cultura a que Walter Benjamin faz referência, a dos oprimidos, dos excluídos e que subsiste carregada de horrores, de medo, de perseguição e repressão. Porque são vistos como "classes perigosas". Neste sentido, é que nos referimos à idéia instrumental de cultura, como um reflexo "(...) do modo de produção, como um conjunto de aparências sociais assumidas por forças materiais que de algum modo possuem sua própria personalidade e necessidade (...)". (SAHLINS, 1992:10). Em outros termos, esta parece "(...) a única via possível para que as práticas sociais e políticas saiam dessa situação, (...) para que elas trabalhem para a humanidade e não mais para um simples reequilíbrio permanente do Universo das semióticas capitalísticas. (...). O que condena o sistema de valorização capitalístico é seu caráter de equivalente geral, que aplaina todos os outros modos de valorização, os quais ficam assim alienados à sua hegemonia". (GUATARRI, op cit:51/52).
Então, esse "modo de produção" tem a ver com os bens culturais simbólicos de consumo e não apenas bens artísticos e intelectuais. Pensar a (pós) modernidade por esse viés, possibilita-nos descentralizar a visão tradicional em que "o capitalismo foi (é) uma influência globalizante fundamental, precisamente por ser uma ordem econômica e não política". (GIDDENS, A. op cit:74). O sistema capitalista nesta acepção, não permitiu que as diferentes culturas florescessem livremente. Porque as arenas onde as políticas de maior importância são elaboradas, sempre tenderam a excluir as verdades dos corpos tombados ou da maioria. É é precisamente estas verdades (cultura submersa) que têm resistido secularmente, que está habilitada para elaborar e sedimentar um novo projeto de modernidade com contornos utópicos.

É preciso ter claro, conforme assegurou Nestor Canclini, (CANCLINI, 1989) que o "ser moderno" perdeu seu sentido neste tempo, exatamente porque as filosofias da (pós) modernidade desqualificam os diferentes movimentos culturais, os quais prometem utopias. Concordamos com ele, quando diz ser necessário trabalhar conjuntamente as disciplinas que estudam de modo separado os temas culturais. Isso é válido para a história da arte e a literatura que se ocupam do culto; o folclore e as ciências sociais que se ocupam da cultura popular; os trabalhos sobre comunicação, especialmente a cultura de massa. É ainda interessante o que ele classifica de ciências sociais nômades. Ou seja, a capacidade dessas em circular pelas diferentes áreas culturais, numa visão interdisciplinar.

Ainda que Canclini esteja analisando as culturas híbridas que qualificam a modernidade e o perfil específico da América Latina, é possível também utilizar tal perspectiva para refletirmos as especificidades, em termos de países, de regionalidade, localidade, etc. Quer dizer, o enfoque da heterogeneidade cultural, onde novos atores políticos devem emergir com suas identidades e prerrogativas que dêem sustentação a um novo projeto mais comum à sociedade.

De acordo com Manzini-Covre, realizar tal projeto é viável, posto que "o uso do espaço permitido pela democracia sob o capitalismo para a construção da cidadania depende dos sujeitos sociais e de seus valores". (COVRE, op cit.:123). Observamos, neste aspecto, que os vários movimentos sócio-culturais ${ }^{1}$ no Brasil têm despontado recentemente como alternativas de mudanças, como formas de combate e de resistência à exclusão social. Esses movimentos têm dado uma

\footnotetext{
Observe os movimentos: Ação e Cidadania: Contra a Miséria e pela Vida, liderado pelo sociólogo Herbert de Souza e lançado em setembro de 1993. O Viva Rio, liderado pelo antropólogo Rubens Cesar Fernandes. O primeiro conseguiu que, pelo menos, uma parcela significativa da sociedade se voltasse para o problema da exclusão social. No Rio de Janeiro, obteve-se resultados surpreendentes em termos de solidariedade por parte da sociedade, onde profissionais de diferentes formações colocaram-se à disposição para realizarem tarefas que contribuíssem para o melhoramento das condições de vida, das parcelas mais carentes. A autora em questão, junto com mais quatro professoras, mantêm há quatro anos um curso de alfabetização para adultos nesta cidade, o que se justifica, pela nossa defesa da cultura enquanto um instrumento de transformação. O Viva Rio surgiu após as duas chacinas ocorridas no estado fluminense: da Candelária (1992), ocasião em que seis crianças e um adulto foram mortos e a de Vigário Geral, também neste ano, quando 22 pessoas foram assassinadas por policiais militares enquanto dormiam. Como conseqüencia, foram criadas a Casa da Paz nesta Favela e a Fábrica da Esperança na Favela de Acari. Atividades culturais das mais diversas, realizam-se nestes locais, onde o alvo são as próprias populações.
} 
dimensão preciosa à cultura popular de massa, no que diz respeito aos usos que dela fazem os indivíduos e principalmente os grupos sociais específicos.

É pertinente aqui descrever um exemplo desses grupos sociais que é o grupo cultural Olodum. Ele contempla "(...) 165 associações num espaço de $6 \mathrm{~km}$. Dentre as setenta ligadas à cultura, ao lazer e ao esporte (...) existem vários setores de atividade cultural e social, voltados ou para o mercado ou para sua comunidade local, o bairro Maciel-Pelourinho-Salvador. A Fundação Olodum (...) ativa projetos em dois setores: o Rufar dos Tambores responsável pelos (...) grupos de dança e teatro, e a Escola Criativa Olodum, que oferece às crianças do bairro uma formação complementar à da escola convencional (...)". (MIRA, op cit:148). Enquanto uma ONG (Organização Não Governamental), o Olodum soube ocupar um espaço para "(...) a melhoria da qualidade de vida da população do Maciel-Pelourinho, para a pesquisa das raízes da cultura negra, para a formação de novos artistas, para que as crianças da comunidade cheguem ao fim do milênio sabendo usar o computador e valorizar suas tradições". (op cit.:149).

Outro exemplo de ONG com esse perfil é o CEAP - Centro de Articulação de Populações Marginalizadas/ RJ. Essa entidade se subdivide em programas, procurando ressaltar o caráter específico de segmentos sociais como: a criança de rua, a mulher negra, enfim, as populações faveladas que não encontram eco nos órgãos oficiais. De uma certa forma, organizações como estas procuram juntar forças para resistir.ao aumento abrupto do monopólio econômico e cultural. O que por outro lado, evidencia a construção de uma cidadania com identidades e valores específicos.

\section{VISLUMBRANDO UMA NOVA UTOPIA QUE REENCANTE O HOMEM}

Em síntese, é esta estratégia, onde o papel intermediário cultural precisa abranger diferentes setores. E, portanto, estendido a sociedade como um todo, caso contrário, não conseguiremos vislumbrar uma utopia que reencante novamente o homem. Como destacou Giddens, a cultura é uma das dimensões da (pós) modernidade, e segundo suas próprias palavras, pode oferecer, potencialmente, uma maneira superior de análise, com a qual mapear o universo cultural moderno. Refletir sobre uma (pós) modernidade que seja menos centrada na razão tecnocrática e na sua objetividade, implica em rever a crise que permeia os valores humanos. E aí, voltamos novamente a Marshal Berman, à metáfora do Fausto Goethiano, como uma figura da cultura moderna. Berman diz que "a heroicidade do Fausto, provém da liberação de tremendas energias humanas reprimidas, não só nele (...) mas em todos os que ele toca e, (...) em toda a sociedade a sua volta (...)". (BERMAN, op cit.:42).

Formalizamos algumas interrogações para tentar sintetizar as idéias expostas até aqui. Que tipo de utopia podemos estabelecer como projetos orientados para o futuro, que possam vincular-se aos rumos imanentes de desenvolvimento e, portanto, possíveis de se realizar? Será que qualquer projeto ou programa econômico alternativo que incorpore os milhões de trabalhadores que não participam do mercado, terá que ser feito dentro da ordem que aí está? Como é possivel resistir a onda devastadora do capitalismo e cuja lógica deveria iniciar a desmontagem do padrão de acumulação capitalista no país? Como é possível pensar numa ação que não impeça o avanço tecnológico, mas o faça em bases reais, onde a técnica seja o meio para atingir o desenvolvimento humano? Como é possível um caminho alternativo que recupere valores socialistas originais, verdadeiramente emancipadores? Que não aceite uma globalização e uma integração imposta pela lógica do sistema capitalista, integradora para fora e desintegradora para dentro? Como é possível, hoje, articular valores inspirados num projeto que olhe para uma sociedade para além desse sistema, mas que dê respostas imediatas para a barbárie que assola o cotidiano do ser que vive do trabalho? Enfim, como superar um caminho meramente doutrinário e buscar a difícil e imprescindível articulação entre interesses imediatos e uma ação estratégica, de longo prazo, com contornos anti-capitalista?

Certamente estamos vislumbrando uma utopia, o que implica, por outro lado, questionarmos: que tipo de sistema social sintetizaria ou abarcaria todas essas interrogações? O que, na realidade, seria o coroamento da (pós) modernidade, não seria um novo tipo de socialismo extraído dos "poderes ocultos" dos seres humanos? Ou, relembrando Benjamim: como evitar que os despojos dos bens culturais dos marginalizados e seus corpos continuem prostrados no chão?

Embora há a impossibilidade de responder a essas questões, algumas conjecturas são possíveis delinear, principalmente, considerando as perspectivas até aqui desenvolvidas. É pertinente, mais uma vez, citar Giddens quando ele aposta nos diversos movimentos sociais como alternativa de transformação. Por exemplo, os ecológicos, os movimentos de contra-cultura, os trabalhistas e tantos outros que são associações ou ONGs contestatórias, cujas origens e campo de ação estão ligados à crítica da difusão do capitalismo excludente e aniquilador da subjetividade humana. Pode ser que a afinidade entre o ideal cultural do auto-desenvolvimento e o efetivo movimento social na direção do desenvolvimento econômico seja o começo, conforme adverte Berman, ao se referir ao Fausto de Goethe. Para ele, esses dois modos de desenvolvimento devem caminhar juntos, devem fundir-se em apenas um.

\section{CONCLUSÃO}

Finalmente, para concluir esta breve análise, frisamos que as críticas feitas à (pós) modernidade, no caso específico do Brasil, tem ressoado como a vitória do capitalismo e da globalização. Na verdade, o uso dessas metáforas, representa, a nosso ver, um exercício de manipulação por parte do discurso dominante, onde "(...) moderno é o mercado, a produtividade, a 
integração, a negociação, o acordo, a conciliação, a concentração (...)". (ANTUNES, 1995:149). Disto resulta que inexiste a subjetividade do sujeito, a cultura e os direitos sociais mais elementares. Vemos, portanto, que urge reelaborar uma nova utopia, onde conceitos metafóricos emergem para explicar uma "nova realidade" que, contraditoriamente, ainda mantêm os mesmos problemas de exclusão social. É neste sentido que, "(...) no plano dos indivíduos (a subjetividade, a felicidade e realização como pessoas não identificadas mecanicamente como o coletivo). (...). Esses personagens que assim se portam são aqueles em que vejo estarem sob o processo de revolução nas próprias subjetividades. Mudanças de valores (...), a 'revolução' que empreendemos no mundo contemporâneo é uma revolução cultural, e então é neste âmbito que tem de se mudar a cultura política, se ainda se quer fazer prevalecer um projeto democrático de real modernidade no Brasil". (COVRE, op cit.:146).

Em suma, respondendo a pergunta título deste trabalho, e como procuramos apontar, compete à cultura, nas suas diferentes manifestações, realizar o ideal de uma nova utopia.

É preciso refutar a tese amplamente difundida de que as ideologias e a história estão mortas, não vemos veracidade neste discurso, tendo em vista que "(...) diante do espetáculo das enormes desigualdades, tão desproporcionais quanto injustificadas, entre ricos e pobres, entre quem tem poder, vale dizer, capacidade de determinar o comportamento dos outros, seja na esfera econômica, seja na esfera política e ideológica (...). Desigualdades particularmente visíveis (...)" (BOBBIO, 1995:125) que ao invés de enterrar a história e seus conflitos, deixam ainda mais a mostra, acirrando com mais intensidade as contradições que, a ordem globalizada faz de conta ignorar. Por outro lado, não se pode deixar de reconhecer a urgência de que a própria esquerda - ela que é o alvo do discurso do fim da história - se faça uma autocrítica, tendo em vista que, há "(...) enormes limitações da chamada esquerda tradicional (...)" (ANTUNES, op cit.:112) para dar conta das questões aqui expostas. Essa "(...) é uma tarefa monumental, e para a qual só uma esquerda social, renovada crítica e radical, de nítida inspiração marxiana, poderá implementar. A esquerda tradicional (do marxismo da era staliniana e stalinista) e a esquerda social-democrática estão, ambas, impossibilitadas para essas empreitadas (...)". (op cit.).

SOARES, FRANCISCA V. The utopia reconstruction: Who is this task due to? Semina: Ci.

Soc./Hum., Londrina, v. 17, n. 3, p. 260-265, Sep. 1996.

ABSTRACT: The article is a reflection about the modernism and of the globalization and its/their consequences on the society. Its/their principal idea is to repose on the fact that the culture can be used to review these problems essentially, in the accomplishment of the construction of the new utopia.

\section{KEY-WORDS: Modernity, Post-modernity, Globalization, Ideology, Utopia, Culture, Subjectivity, Capitalism, Socialism, Liberalism, The Left Wing.}

\section{REFERÊNCIAS BIBLIOGRÁFICAS}

ANTUNES, Ricardo (1995). Adeus ao Trabalho? Ensaio sobre as Metamorfoses e a Centralidade do Mundo do Trabalho, SP, Cortez.

BELLAH, Robert N. (1986). A Nova Consciência Religiosa e a Crise da Modernidade. In RELIGIÃO E SOCIEDADE, RJ, ISER.

BENJAMIN, Walter (1986). Magia e Técnica, Arte e Política. Obras Completas, vol. I, SP, Brasiliense.

BERMAN, Marshal (1986). Tudo que é Sólido Desmancha no Ar: A Aventura da Modernidade, SP, Companhia das Letras.

BOBBIO, Norberto (1995). Direita e Esquerda, SP, UNESP.

CANCLINI, Nestor (1989). Culturas Híbridas: Estratégias para Entrar y Sair de la Modernidad, México, Grijalbo.

COVRE-MANZINE, Ma. de Lourdes (1983). A Fala dos Homens: Análise do Pensamento Tecnocrático (1964/1984, $\mathrm{SP}$, Brasiliense.

(1994). Cidadania, Cultura e Sujeitos. In A CIDADANIA EM CONSTRUÇÄO, Mary Spink (org.) RJ, Cortez.

CARVALHO, Edgar de A. (1994). O Reencantamento do
Homem. In REVISTA MARGEM, PUC/SP.

CASTAÑEDA, Jorge (1994). Utopia Desarmada (Intrigas, dilemas, Promessas da Esquerda Latino-Americana), SP, Companhia das Letras.

FEATHRSTONE, Mike (1994). Para uma Sociologia da Cultura Pós-Moderna. In REVISTA BRASILEIRA DE CIÊNCIAS SOCIAIS, 25.

GIDDENS, Anthony (1991). As Conseqüências da Modernidade. SP, UNSEP.

GRAMSCI, Antonio (1979). Os Intelectuais e a Organização da Cultura. RJ, Civilização Brasileira.

GUATARRI, Félix (1993). As Três Ecologias. SP, Papirus.

HABERMAS, Junger. Modernidad: Um Projecto Incompleto. In EL DEBATE DE LA MODERNIDAD E PÓS-MODERNIDAD. Enicollas Casullo (org), México, Puntosur.

LÉPINE, Claude (1974). O Inconsciente na Antropologia de Lévi-Strauss, SP, Ática.

LYOTARD, Jean F. (1994). O Pós-Moderno. RJ, José Olympio 